\title{
Correlation between leukocyte count and infarct size in ST segment elevation myocardial infarction
}

\author{
Júlia Peixoto Ferrari ${ }^{1}$, Maria Emília Lueneberg² ${ }^{2}$ Roberto Leo da Silva², Tammuz Fattah², \\ Carlos Antônio Mascia Gottschall3, Daniel Medeiros Moreira²
}

1Universidade do Sul de Santa Cataria - Unisul, Palhoça, Brazil
${ }^{2}$ Instituto de Cardiologia de Santa Catarina - ICSC, São José, Brazil
${ }^{3}$ Instituto de Cardiologia do Rio Grande do Sul - IC-FUC, Porto Alegre, Brazil

Submitted: 7 April 2016

Accepted: 13 June 2016

Arch Med Sci Atheroscler Dis 2016; 1: e44-e48

DOI: 10.5114/amsad.2016.60759

Copyright @ 2016 Termedia \& Banach

\section{Abstract}

Introduction: Regarding the inflammatory mechanisms involved in ischemic heart disease, currently the leukocyte count is the subject of studies related to its association with the prognosis and mortality of ST segment elevation myocardial infarction (STEMI). Our aim is correlate the leukocyte count rise with the size of STEMI, evaluated with the area under the curve (AUC) and the peak of necrosis markers release.

Material and methods: This study is a sub-analysis of the TETHYS trial, a clinical trial that evaluated the effects of methotrexate in STEMI. We evaluated the correlation between quantitative variables with Pearson's correlation, and the variables that did not follow a normal distribution were subjected to logarithmic transformation to base 10. The value of $p<0.05$ indicated statistical significance.

Results: Males accounted for $73 \%$ of the participants, who had an average age of 59 years. A total of $58 \%$ were hypertensive and $53 \%$ smokers. The leukocyte count at hospital admission was significantly correlated with the AUC creatine kinase (CK) $(r=0.256, p=0.021)$, troponin AUC $(r=0.247$, $p=0.026)$, peak CK $(r=0.270, p=0.015)$ and troponin peak $(r=0.233$, $p=0.037)$. The leukocyte count at $72 \mathrm{~h}$ was significantly correlated with CK AUC $(r=0.238, p=0.032)$, AUC of MB portion of CK $(r=0.240, p=0.031)$ and peak CK $(r=0.224, p=0.045)$.

Conclusions: White blood cell count correlates with STEMI size assessed by serial cardiac biomarker levels.

Key words: myocardial infarction, leukocyte count, leukocyte.

\section{Introduction}

Ischemic diseases cause one of every six deaths. Every $34 \mathrm{~s}$ an American experiences a coronary event, and every minute, another dies due to the same factor [1]. Acute myocardial infarction is one of the consequences of ischemic diseases and has in its pathophysiological process a clear inflammatory involvement: there is an increase of nuclear factor $\kappa \mathrm{B}(\mathrm{NF}-\kappa \mathrm{B})$ and the levels of proinflammatory cytokines, and there is adherence of polymorphonuclear leucocytes [2]. There is also an increase in the number of leukocytes after the onset of symptoms of ischemic disease, and it is much larger when there are significant injuries [3]. These factors have stimulated the search for potential anti-inflammato-

\author{
Corresponding author: \\ Daniel Medeiros Moreira \\ Instituto de Cardiologia \\ de Santa Catarina - ICSC \\ Rua Adolfo Donato da Silva \\ Praia Comprida \\ 88103-901 São José, Brazil \\ Phone: +554884175590 \\ E-mail: \\ danielmedeirosmoreira@ \\ gmail.com
}


ry therapeutic targets for cardiovascular disease [4-12].

Based on the existence of this mechanism, currently, the blood leukocyte count is the subject of studies, not only in order to characterize it as an inflammatory marker, a fact that is proven, but also as a way to prove its relationship with cardiac events [13], increased mortality [14-16] and severity of myocardial infarction $[17,18]$. In addition, it has been shown, too, that an increased white blood cell count signals a period of increased risk for recurrent ischemic events, where this increase precedes the risk by a week, and is associated with increased in-hospital mortality [19-21].

Although studies have already related the WBC count to the severity of myocardial infarction [17, 18] and increased mortality [14-16, 20], no one has correlated directly leukocyte count with the size of acute myocardial infarction with STEMI. Given this gap in the knowledge, this study presents the hypothesis that there is a correlation between leukocyte count and the STEMI size estimated by the area under the curve of myocardial necrosis markers. This correlation could represent an important new risk stratification and prognostic tool for patients who suffer STEMI.

\section{Material and methods}

It is a cross-sectional study constituting a subanalysis of the study Methotrexate Therapy in ST Segment Elevation Myocardial Infarctions: a randomized double-blind, placebo-controlled trial (TETHYS trial), whose design has been described previously [13]. An evaluation of the data of 81 patients with a diagnosis of confirmed STEMI who were included in the study from April 2013 to June 2014 was performed.

Following the criteria of the TETHYS study, included patients had to be older than 18 years, with chest pain suggestive of acute myocardial infarction that started within $12 \mathrm{~h}$, electrocardiogram showing elevation of the ST segment $\geq 2 \mathrm{mV}$ at a minimum of two consecutive times, and primary angioplasty. Excluded were patients with previous myocardial infarction, heart failure history, angioplasty in the last 3 months, heart failure or cardiogenic shock, previous renal failure (serum creatinine $>2 \mathrm{~g} / \mathrm{dl}$ ), alcohol consumption ( $\geq 20$ drinks per week), illegal drug use, rheumatoid arthritis, cancer, infectious diseases, prior anemia (hematocrit below 30\%), use of steroidal anti-inflammatory or nonsteroidal drugs in the last week, excessive consumption of xanthine (more than two and a half glasses of coffee or two and a half gourds of mate and pregnancy.

The primary endpoint in this study was the correlation of leukocyte count (on admission and $72 \mathrm{~h}$ ) with infarct size measured by the area under the curve (AUC) of creatine kinase (CK). Secondary outcomes included the correlation of WBC count with the AUC of MB portion of CK (CK-MB) mass and troponin I, the white blood cell count with CK, CK-MB mass and troponin peaks and the white blood cell count with left ventricular ejection fraction (LVEF). The infarct size measured by AUC of CK, CK-MB and troponin I was calculated by the linear-trapezoidal method from the serum measurements taken every $6 \mathrm{~h}$ for $72 \mathrm{~h}$. If the baseline or $72 \mathrm{~h}$ measurements were unavailable, the corresponding value was set to 0 . For missing values at intermediate times, linear interpolation was used. The infarct size was also evaluated by CK peaks, CK-MB and troponin I. The WBC count was assessed on admission and at $72 \mathrm{~h}$. All samples were analyzed in the local laboratory. Left ventricular ejection fraction was assessed by transthoracic echocardiography (Vivid E9 system, General Electrics) at $72 \mathrm{~h}$ and after 3 months. Mortality was assessed at 3 months.

\section{Statistical analysis}

Data were analyzed with SPSS 13.0 software. Continuous variables were presented as the mean and standard deviation or median and interquartile range when they did not follow a normal distribution, whereas qualitative variables were presented as the absolute number and percentage. Fisher's exact test was used to evaluate categorical variables, whereas Student's $t$ test for independent samples was used to evaluate continuous variables. The correlation between quantitative variables was assessed by Pearson's correlation, and variables that did not follow a normal distribution were subjected to logarithmic transformation to base 10 for further evaluation with Pearson's correlation. The value of $p<0.05$ indicated statistical significance. The study was approved by the local ethics committee.

\section{Results}

We evaluated 81 patients who were enrolled in the study from April 2013 to June 2014. The sample consisted of 59 (72\%) men. The remaining basic characteristics of the population, mean leukocyte count as well as the median AUC and peak cardiac biomarkers are presented in Table I.

The correlation between WBC count with areas under the curve and peaks of cardiac biomarkers is presented in Table II. The correlation between logarithmic transformation of AUC CK with admission leukocyte count and leukocyte count at $72 \mathrm{~h}$ showed a significant but weak positive correlation $(r=0.256, p=0.021$ and $r=0.238, p=0.032$, respectively). Similarly, there is a correlation between admission leukocyte count and logarithmic trans- 
Table I. Characteristics of patients at baseline

\begin{tabular}{|c|c|}
\hline Variables & Values \\
\hline Age $\left[\right.$ years] ${ }^{*}$ & $59 \pm 11.4$ \\
\hline Men, $n(\%)$ & $59(73)$ \\
\hline \multicolumn{2}{|l|}{ Risk factors, $n$ (\%): } \\
\hline Hypertension & $47(58)$ \\
\hline Dyslipidemia & $27(33)$ \\
\hline Smoking & $43(53)$ \\
\hline $\begin{array}{l}\text { Family history of coronary } \\
\text { disease }\end{array}$ & $24(29)$ \\
\hline Anterior wall involvement, $n(\%)$ & $32(39)$ \\
\hline \multicolumn{2}{|l|}{ Infarct size - median (IQR): } \\
\hline AUC CK & $\begin{array}{c}74448 \\
(43276.5-103338)\end{array}$ \\
\hline AUC CK-MB & $\begin{array}{c}9423.3 \\
(3808.2-12387.1)\end{array}$ \\
\hline AUC troponin & $\begin{array}{c}3193.5 \\
(1278.9-5675.9)\end{array}$ \\
\hline CK peak & $\begin{array}{c}2446 \\
(1305.5-3665.5)\end{array}$ \\
\hline CK-MB peak & $\begin{array}{c}469.8 \\
(204.2-646.5)\end{array}$ \\
\hline Troponin I peak & $\begin{array}{c}106.3 \\
(41.2-223.5)\end{array}$ \\
\hline Admission leukocyte count* & $13294 \pm 4632$ \\
\hline Leukocyte count at $72 \mathrm{~h}^{*}$ & $9320 \pm 3048.5$ \\
\hline
\end{tabular}

*Values expressed as mean \pm standard deviation; $I Q R$-interquartile range, $A \cup C$ - area under the curve, $C K$ - creatine kinase, CK-MB $M B$ portion of $C K$.

Table II. Correlation between infarct size and leukocyte count*

\begin{tabular}{|lcccc|}
\hline Infarct size & \multicolumn{2}{c}{$\begin{array}{c}\text { Admission } \\
\text { leukocyte count }\end{array}$} & \multicolumn{2}{c|}{$\begin{array}{c}\text { Leukocyte } \\
\text { count }\end{array}$} \\
\cline { 2 - 5 } & $r$ & $p$ & $r$ & $p$ \\
\hline Log AUC CK & 0.256 & 0.021 & 0.238 & 0.032 \\
\hline Log AUC CK-MB & 0.207 & 0.064 & 0.240 & 0.031 \\
\hline Log AUC troponin & 0.247 & 0.026 & 0.198 & 0.077 \\
\hline Log peak CK & 0.270 & 0.015 & 0.224 & 0.045 \\
\hline Log peak CK-MB & 0.185 & 0.097 & 0.195 & 0.081 \\
\hline Log peak troponin & 0.233 & 0.037 & 0.174 & 0.120 \\
\hline
\end{tabular}

*Logarithmic transformation to base 10; AUC - area under the curve, $C K-$ creatine kinase, $C K-M B-M B$ portion of $C K$.

formation of AUC troponin, and peaks of CK and troponin. There is a correlation between leukocyte count at $72 \mathrm{~h}$ and logarithmic transformation of AUC CK-MB and CK peak (Table II).

In the period of 3 months after the STEMI event, 6 of 81 patients died (7\%). The average white blood cell count on admission was not associated with mortality: for the average patient who died at 3 months it was $13976.6 \pm 6058.6 / \mu$, while for the other patients it was $13239.4 \pm 4546.9 / \mu \mathrm{l}$ $(p=0.710)$. Likewise, at $72 \mathrm{~h}$ the mean leukocyte count of patients who died within 3 months was $12181.6 \pm 5476.5 / \mu \mathrm{l}$, and for other patients it was $9092 \pm 2702.5 / \mu \mathrm{l}(p=0.227)$.

There was no significant correlation between WBC count on admission and ventricular function assessed by ejection fraction of the left ventricle: LVEF at $72 \mathrm{~h}$ showed $r=-0.053, p=0.640$ and LVEF at 3 months $r=-0.093, p=0.420$. The leukocyte count at $72 \mathrm{~h}$ did not show a significant correlation with LVEF: LVEF at $72 \mathrm{~h}$ showed $r=-0.066, p=0.560$ and LVEF at 3 months $r=-0.015, p=0.890$

\section{Discussion}

Our study has important findings relating leukocyte count and STEMI size measured by cardiac biomarkers.

Despite the fact that the study in question did not use imaging tests such as myocardial magnetic resonance imaging (MRI), assessment of infarct size by AUC of myocardial necrosis markers release is widely known and used, even as an endpoint in randomized controlled trials $[4,7]$. With some exceptions, the logarithmic transformation of AUC of biomarkers and the peaks of these markers show positive correlations with the leukocyte count at admission and at $72 \mathrm{~h}$. Case-control studies in previously healthy patients have shown an association between WBC count and coronary heart disease: a leukocyte count greater than 8000 apparently has a stronger association with coronary heart disease [22, 23]. Other studies have shown that white blood cell count of patients with myocardial infarction is independently associated with mortality and in-hospital medical complications, as well as a higher incidence of congestive heart failure and death [24, 25].

The reason for the association of WBC count with unfavorable outcomes and poor prognosis in myocardial infarction is based primarily on inflammation caused by a coronary event. The mechanisms of the increase in inflammatory cells and active secondary leukocytes range from biochemical, biomechanical and hematological to electrical. It was reported that leukocytes are able to cause oxidative and proteolytic injury of the coronary arteries, being able to aggregate, impacting the microvasculature, and causing hypercoagulable and electrical instability in the heart [26]. All these mechanisms lead to lower coronary perfusion and therefore increased size and severity of the event.

Despite the correlation between infarct size and leukocyte count, there was no significant 
correlation between leukocyte and ventricular function assessed by echocardiography. These findings were unexpected, and contrast with the results showing correlations between logarithmic transformation of AUC and biomarker peaks. Furthermore, the findings differ from the literature, which indicates a negative correlation between the leukocyte count and the function of the left ventricle [27].

This study has some limitations that should be mentioned: despite adequate power to assess substitute outcomes, there was a lack of power to demonstrate the association between mortality at 3 months and WBC count. New studies with longterm follow-up as well with a larger sample may demonstrate that such a relationship might have a greater impact, agreeing then with the literature. The limitations, however, do not invalidate the data; from the results obtained in this study one can use the patient's white blood cell count with STEMI as another prognostic tool, allowing stratification even if it is more detailed and specific, allowing then a more targeted and individualized treatment.

In conclusion, the WBC count of admission relates to the STEMI size assessed by AUC CK, AUC troponin, CK peak and troponin peak. Already the WBC count at $72 \mathrm{~h}$ correlates with the size of STEMI as measured by AUC CK, AUC CK-MB and CK peak. The white blood cell count has no association with mortality or left ventricular function in this study.

\section{Conflict of interest}

The authors declare no conflict of interest.

\section{References}

1. Go AS, Mozaffarian D, Roger VL, et al. Heart disease and stroke statistics--2013 update: a report from the American Heart Association. Circulation 2013; 127: 6-245.

2. Frangogiannis NG, Smith CW, Entman ML. The inflammatory response in myocardial infarction. Cardiovasc Res 2002; 53: 31-47.

3. Coller BS. Leukocytosis and ischemic vascular disease morbidity and mortality: is it time to intervene? Arterioscler Thromb Vasc Biol 2005; 25: 658-670.

4. Piot C, Croisille P, Staat P, et al. Effect of cyclosporine on reperfusion injury in acute myocardial infarction. $N$ Engl J Med 2008; 359: 473-81.

5. Moreira DM, Vieira JL, Gottschall CA. The effects of METhotrexate therapy on the physical capacity of patients with ISchemic heart failure: a randomized double-blind, placebo-controlled trial (METIS trial). J Card Fail 2009; 15: 828-34

6. Couzin-Frankel J. Massive trials to test inflammation hypothesis. Science 2012; 337: 1158.

7. Moreira DM, Lueneberg ME, da Silva RL, Fattah T, Mascia Gottschall CA. Rationale and design of the TETHYS trial: the effects of methotrexate therapy on myocardial infarction with ST-segment elevation. Cardiology 2013; 126: 167-70.
8. Klingenberg R, Luscher T. Inflammation in coronary artery disease and acute myocardial infarction-is the stage set for novel therapies? Curr Pharm Des 2012; 18: 4358-69.

9. Testa L, Van Gaal WJ, Bhindi R, et al. Pexelizumab in ischemic heart disease: a systematic review and meta-analysis on 15,196 patients. J Thorac Cardiovasc Surg 2008; 136: 884-93.

10. Dinarello CA. Anti-inflammatory agents: present and future. Cell 2010; 140: 935-50.

11. Dobaczewski M, Gonzalez-Quesada C, Frangogiannis NG. The extracellular matrix as a modulator of the inflammatory and reparative response following myocardial infarction. J Mol Cell Cardiol 2010; 48: 504-11.

12. Kempf T, Zarbock A, Vestweber D, Wollert KC. Anti-inflammatory mechanisms and therapeutic opportunities in myocardial infarct healing. J Mol Med 2012; 90: 361-9.

13. Chia S, Nagurney JT, Brown DFM, et al. Association of leukocyte and neutrophil counts with infarct size, left ventricular function and outcomes after percutaneous coronary intervention for ST-elevation myocardial infarction. Am J Cardiol 2009; 103: 333-7.

14. Lofmark R, Nordlander R, Orinius E. The temperature course in acute myocardial infarction. Am Heart J 1978; 96: 153-6.

15. Grzybowski M, Welch RD, Parsons L, et al. The association between white blood cell count and acute myocardial infarction in hospital mortality: findings from the National Registry of Myocardial Infarction. Acad Emerg Med 2004; 11: 1049-60.

16. Palmerini T, Généreux P, Mehran R, et al. Association among leukocyte count, mortality, and bleeding in patients with non-ST-segment elevation acute coronary syndromes (from the Acute Catheterization and Urgent Intervention Triage StrategY [ACUITY] Trial). Am J Cardiol 2013; 111: 1237-45.

17. Cole DR, Singian EB, Katz LN. The long-term prognosis following myocardial infarction, and some factors which affect it. Circulation 1954; 9: 321-34.

18. Swirski FK, Nahrendorf M. Leukocyte behavior in atherosclerosis, myocardial infarction, and heart failure. Science 2013; 339: 161-6.

19. Grau AJ, Boddy AW, Dukovic DA, et al. Leukocyte count as an independent predictor of recurrent ischemic events. Stroke 2004; 35: 1147-52.

20. Pesaro AEP, Nicolau JC, Serrano Jr CV, et al. Influence of leukocytes and glycemia on the prognosis of patients with acute myocardial infarction. Arq Bras Cardiol 2009; 92: 88-93.

21. Kosuge M, Kimura K, Morita S, et al. Combined prognostic utility of white blood cell count, plasma glucose, and glomerular filtration rate in patients undergoing primary stent placement for acute myocardial infarction. Am J Cardiol 2009; 103: 322-7.

22. Friedman GD, Klatsky AL Siegelaub AB. The leukocyte count as a predictor of myocardial infarction. N Engl J Med 1974; 290: 1275-8.

23. Manttari M, Manninen V, Koskinen P, et al. Leukocytes as a coronary risk fator in a dyslipidemic male population. Am Heart J 2003; 44: 201-11.

24. Barron HV, Harr SD, Radford MJ, Wang Y, Krumholz HM. The association between white blood cell count and acute myocardial infarction mortality in patients $>$ or $=65$ years of age: findings from the cooperative cardiovascular project. J Am Coll Cardiol 2001; 38: 1654-61.

25. Barron HV, Cannon CP, Murphy AS, Braunwald E, Gibson M. Association between white blood cell count, epicardial blood flow, myocardial perfusion, and clinical 
Outcomes in the setting of acute myocardial infarction. A thrombolysis in myocardial infarction 10 study. Circulation 2000; 102: 2329-34.

26. Madjid M, Awan I, Willerson JT, Casscells W. Leukocyte count and coronary heart disease. J Am Coll Cardio 2004; 44: 1945-56

27. Chia A, Nagurney JT, Brown DFM, Raffel C, Bamberg D. Association of leukocyte and neutrophil counts with infarct size, left ventricular function and outcomes after percutaneous coronary intervention for ST-elevation myocardial infarction. Am J Cardiol 2009; 103: 333-7. 